\title{
Nip New Disease Reports \\ Potato spindle tuber viroid detected in seed of uncultivated Solanum anguivi, S. coagulans and $S$. dasyphyllum collected from Ghana, Kenya and Uganda
}

A. Skelton ${ }^{1} *$, A. Buxton-Kirk ${ }^{1}$, A. Fowkes ${ }^{1}$, V. Harju ${ }^{1}$, S. Forde ${ }^{1}$, R. Ward ${ }^{1}$, L. Frew ${ }^{1}$, O. Wagstaff ${ }^{2}$, T.R. Pearce $^{2}$, J. Terry ${ }^{2}$, J.

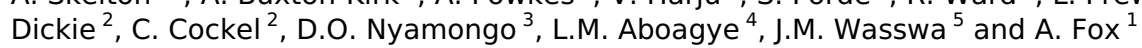

${ }^{1}$ Fera Science Ltd., Sand Hutton, York YO41 1LZ, UK; ${ }^{2}$ The Royal Botanic Gardens, Kew, Millennium Seed Bank, Wakehurst Place, Ardingly, West Sussex, RH17 6TN; ${ }^{3}$ Kenya Genetic Resources Research Institute, Nairobi, Kenya; ${ }^{4}$ Plant Genetic Resources Research Institute, Bunso, Ghana; ${ }^{5}$ Plant Genetic Resources Centre, Entebbe, Uganda

*E-mail: anna.skelton@fera.co.uk

Received: 01 Apr 2019. Published: 20 Jun 2019.

Adapting Agriculture to Climate Change (Crop Wild Relatives) is a project, jointly managed by the Global Crop Diversity Trust and the Millennium Seed Bank, Royal Botanic Gardens, Kew (RBG Kew). As part of this project, seed of 30 wild taxa related to Solanum melongena (aubergine) were collected from seven countries. These Solanum species grow wild in Africa and are used for food and/or medicinal purposes. No virus or viroid symptoms were seen on the plants at collection. Initial cleaning and drying of collected seed was carried out in-country before being shipped to RBG Kew, where debris was removed, and the samples $\mathrm{x}$ rayed, counted and sealed in universal glass bottles and stored at $-20^{\circ} \mathrm{C}$.

In June 2018, 98 seed samples (100 seeds per sample) of the solanaceous species were sent from RBG Kew to Fera Science Ltd. to be tested for Potato spindle tuber viroid (PSTVd) to facilitate export to the World Vegetable Center, Taiwan for pre-breeding research. This pre-breeding research is the initial step aimed at identifying important genetic diversity within crop wild relatives to enable subsequent breeding of domesticated crops that are better adapted to future climatic conditions. Seed samples were of eight species, namely Solanum anguivi, $S$. anomalum, $S$. cerasiferum, S. coagulans, S. dasyphyllum, S. incanum, S. macrocarpon and $S$. virginianum. Solanum anguivi and $S$. dasyphyllum were considered priority species in the current project, due to the lack of existing collections.

Due to the small consignment size, an initial screen was done on a subsample of 10 seeds per sample. RNA was extracted from the seeds using a magnetic bead extraction method and tested by real-time RT-PCR using an assay that detects PSTVd, Tomato chlorotic dwarf viroid and Tomato planta macho viroid (Boonham et al., 2004). Eight of the samples tested positive using this assay: five samples of $S$. anguivi, two of $S$. dasyphyllum and one of $S$. coagulans. To identify the species of pospiviroid detected, RNA extracts were tested by RT-PCR with a Verso 1-step RTPCR Reddymix kit (Thermo Scientific, USA) using 3H1-F and 2H1-R primers (Shamloul et al., 1997) and pospi $1 \mathrm{FW}$ and pospi $1 \mathrm{RE}$ primers (Verhoeven et al., 2004). Bands were detected of the correct size (c. 196 bp) for all eight samples using the Verhoeven et al. (2004) primers and for three samples using the Shamloul et al. (1997) primers (c. 360 bp). The resulting PCR products were sent for sequencing using the above primer sets (Sequiserve, Germany). PSTVd was confirmed in all eight samples and the sequences added to GenBank (Table 1).

Herbarium specimens collected alongside the seed collections were also tested by real-time RT-PCR using the Boonham et al. (2004) assay. Two of the herbarium samples tested positive and were tested by RT-PCR using

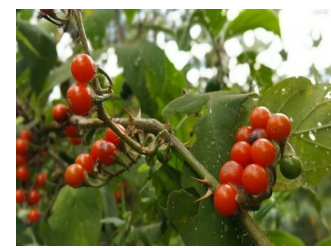

Figure 1

To cite this report: Skelton A, Buxton-Kirk A, Fowkes A, Harju V, Forde S, Ward R, Frew L, Wagstaff O, Pearce TR, Terry J, Dickie J, Cockel C, Nyamongo DO, Aboagye LM, Wasswa JM, Fox A, 2019. Potato spindle tuber viroid detected in seed of uncultivated Solanum anguivi, S. coagulans and S. dasyphyllum collected from Ghana, Kenya and Uganda. New Disease Reports 39, 23. http://dx.doi.org/10.5197/j.2044-0588.2019.039.023

New Disease Reports is a peer-reviewed on-line journal published by the British Society for Plant Pathology for more information visit http://www.ndrs.org.uk/

the Verhoeven et al. (2004) assay. The resulting PCR products were sent for sequencing, PSTVd was identified and sequences added to GenBank (Table 1). The available sequence for the related herbarium and seed samples shared $98-99 \%$ homology.

This is the first report of a pospiviroid being detected in S. anguivi, $S$. coagulans and $S$. dasyphyllum, confirming the potential for pospiviroids to be distributed through non-commercial seed. There are very few reports of PSTVd in Africa; the viroid was detected in Egypt in potato and in Nigeria (CABI, 2018) and in Ghana in tomato (Batuman et al., 2019). These data indicate that PSTVd may be more widely distributed than suggested by current reports. PSTVd-infected seed collections and related herbarium specimens were destroyed or transferred under quarantine licence to Fera Science Ltd. for research purposes.

\section{Acknowledgements}

This testing was funded through the Defra-Fera Long Term Service Agreement. The Adapting Agriculture to Climate Change (Crop Wild Relatives) project is funded by the Government of Norway.

\section{References}

Batuman O, Çiftçi OC, Osei MK, Miller SA, Rojas MR, Gilbertson RL 2019. Rasta disease of tomato in Ghana is caused by the pospiviroids Potato spindle tuber viroid and Tomato apical stunt viroid. Plant Disease (in press). http://dx.doi.org/10.1094/PDIS-10-18-1751-RE

Boonham N, Pérez LG, Mendez MS, Peralta EL, Blockley A, Walsh K, Barker I, Mumford RA, 2004. Development of a real-time RT-PCR assay for the detection of Potato spindle tuber viroid. Journal of Virological Methods 116, 139-146. http://dx.doi.org/10.1016/j.jviromet.2003.11.005

CABI (2018) Potato spindle tuber viroid (spindle tuber of potato) datasheet. CABI Invasive Species Compendium.

https://www.cabi.org/cpc/datasheet/43659. (Accessed 1 April 2019).

Shamloul AM, Hadidi A, Zhu SF, Singh RP, Sagredo B, 1997. Sensitive detection of potato spindle tuber viroid using RT-PCR and identification of a viroid variant naturally infecting pepino plants. Canadian Journal of Plant Pathology 19, 89-96. http://dx.doi.org/10.1080/07060669709500580

Verhoeven JTJ, Jansen CCC, Willemen TM, Kox LFF, Owens RA, Roenhorst JW, 2004. Natural Infections of tomato by Citrus exocortis viroid, Columnea latent viroid, Potato spindle tuber viroid and Tomato chlorotic dwarf viroid. European Journal of Plant Pathology 110, 823-831. http://dx.doi.org/10.1007/s10658-004-2493-5

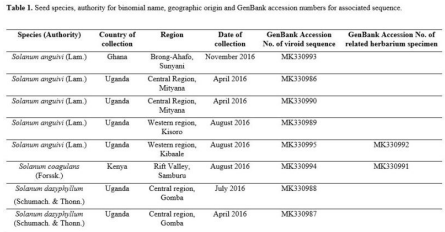

Figure 2 